\title{
What's on Sale? A Discourse Analysis of Four Distinctive Online Escort Advertisement Websites
}

\author{
Kristofor Oscar Burghart ${ }^{1}$
}

Published online: 13 November 2017

(C) The Author(s) 2017. This article is an open access publication

\begin{abstract}
Technological advances have contributed to the changing structure and organisation of sex work, heralding a dramatic growth in sex workers soliciting and advertising the selling of sex via the Internet. This study was concerned with four distinctive, independent online escort markets-male heterosexual, female heterosexual, gay and lesbian. A discourse analysis was conducted on ten online advertisements from each escort sample, in order to analyse how different online escorts advertise their sexual services in relation to gender, sexuality and social class. The findings reveal core differences between each of the escort samples in relation to gender and power dynamics. Findings highlighted that maleness and masculinity-aspower play a role whether we are looking at men as the buyers or the sellers of escort services. In stark contrast, advertisements presented femaleness and femininity as objectified, submissive and/or vulnerable regardless as to whether we are looking at women as the buyers or the sellers of escort services.
\end{abstract}

Keywords Escorts $\cdot$ Advertisements $\cdot$ Gender $\cdot$ Sexuality $\cdot$ Social class

\section{Introduction}

Despite an extensive body of research focusing on the online escort industry, less attention has been directed at male to female, male to male and female to female online escort services, subsections of the sex industry that are experiencing significant growth (Levitt and Venkatesh 2007; Cunningham and Kendall 2009;

Kristofor Oscar Burghart

Kristofor.burghart.2009@live.rhul.ac.uk

1 School of Law, Royal Holloway University of London, Egham Hill, Egham, Surrey TW20 0PZ, UK 
Sharpe and Earle 2003; Weitzer 2010). As a result, we know relatively little with regards to the complex structural divisions and characteristics of the online escort population, in regards to gender, sexuality, age, education, cultural background and health and safety issues (Bernstein 2007; Ray 2007; Weitzer 2007; Young 2008).

In this paper I examine the wider culture of selling adult escort sexual services, and in particular the ways in which online escorts represent, capitalise and exploit their own sexuality through online advertisements, whilst also appealing to the sexual and erotic desires of a range of client groups. The aim of the research was to examine the language and images used within advertisements for escort services, and to explore their role in defining and sustaining the relationship between escort and client. Central to the analysis was an examination of the understanding between the escort and the customer of their individual roles, and the ways in which the language displayed within the advertisement upheld this relationship, with regard to the gender, sexuality and social status of each party. The research was also concerned with how each of the distinctive markets define and categorise modes of sexual production and consumption and how this may be understood in a broader context, where the boundaries between sexual identity, gender roles and selfpresentation via online advertising are increasingly blurred as far as commerce is concerned.

This paper also recognises that it is the customers who shape the supply and demand aspect of online escort markets; subsequently it is the role of the individual escorts to exploit, capitalise and manipulate their use of language to deliberately play into the sexual desires of their preferred customer. In addition, in order not to assume the actual sexuality of the escort and their potential customer, this study does not refer to each of the distinctive escort markets in terms of sexual orientation. Instead, the focus is placed on the gender of the escort and the gender of the customer that they target via their advertisements.

\section{Review of the Literature}

\section{Escort Services and the Internet}

The use of technology to market sexual services and interests has now been widely recognised. According to some researchers Internet technologies and communications have created a space where the wider public and escorts are 'free to play' with gender and sexuality (Bernstein 2007; Ray 2007; Young 2008). As a result, escorts are now able to present themselves, through advertisements, to potential customers in innovative and resistant ways. It has been well documented that the Internet has played a crucial role in altering gendered demand for commercial sexual services (Weitzer 2005). Gender stereotypes surrounding pornographic content and sexual advertisements, which focus on sex as a masculine need, have not only been challenged, but altered to encourage female consumption (Van Zoonen 2002). This has seemingly been reflected within the online escort labour market; catering for different customers' sexualities, whether male or female, and whether heterosexual, bisexual or gay (Capiola et al. 2014; Weitzer 2007). 
As others have documented, the appeal of the Internet is seemingly obvious for sex workers; providing them with the anonymity, convenience, and discretion to target and advertise to a particular type of clientele (Milrod and Martin 2012; Parsons et al. 2004; Sanders 2005; Walby 2012). Online escort advertisement websites have allowed escorts the opportunity to attract and match with clients who otherwise would not have patronised sex workers on the street (Cunningham and Kendall 2009; Ashford 2009), particularly female clients seeking either male or female sex workers (Burghart 2015). As a result, the individual escort could market more resourcefully, by specifically targeting his/her products or services directly to those interested clients they could serve well and most profitably (Holt and Blevins 2007: 334). Subsequently, technological advances in marketing and solicitation have, for the first time, provided male and female sex workers with a platform to market their sexual services to both male and female customers (see Burghart 2015).

The handful of studies which have attempted to examine either online female or gay male escort online advertisements (Castle and Lee 2008; Parsons et al. 2004; Pruitt and Krull 2010) or both female and gay male escorts' online advertisements (Agresti 2009) have so far been limited to a quantitative contextual analysis and the counting of words, rather than interpreting their discourses. In this respect they rarely consider online escort markets in relation to the escort's gender and the sexual orientation of their services. Despite this narrow research focus, such studies have documented substantial differences between heterosexual female and gay online escorts' marketing patterns. Parsons et al. (2004) noted within their study, that gay male escorts were more likely than female escorts to include their preferred sexual activities and physical assets in their biographical profiles. Agresti (2009) also noted that male to male advertisements focused, at times, explicitly on the specifics of the size, shape and description of the escort's genitals, as well as on how male escorts frequently make reference to their role in intercourse within their biographical sketches (i.e. top, bottom, or versatile). Regardless of the differences in explicitness of content, several studies have noted an 'industry standard' for the inclusion of certain information within online escort advertisements; more often than not containing detailed information about the escort, given in the form of a biography or 'stats'. They commonly include a description of the escort's physical measurements and personality dimensions (Castle and Lee 2008; Pruitt and Krull 2010; Sharpe and Earle 2003; Stephens 2009), within the context of exploiting their 'erotic capital' in line with traditional sexual scripts (Hakim 2010). Walthers (1994) suggested that online relationships in cyberspace become more intimate and sociable than those offline. Part of this "hyper-personal" effect derives from people's tendency to present themselves in their best light when only using only written words, due to the absence of visual and auditory cues. As Brents and Hausbeck (2007) have argued, the changing nature of traditional indoor sex markets, due to technological advances, has seen a shift from the so-called McDonaldisation of standardised production and consumption, to an online industry that is willing to capitalise on niche markets through the provision of specialist services and the inclusion of emotional and intimate services for both male and female customers. 
As has been well documented and researched, recent decades have witnessed a dramatic change in sexual attitudes (Scott 1998), relationship formation (Giddens 1992) and sexual behaviour (Wellings et al. 2006). As a result, traditional socialised codes of sexual behaviour of male and female roles has manifested away from traditional notions of Victorian quasi-respectability set out by the ideology of 'romance' and 'love' and courtship (Illouz 1997; Sanders 2008). Instead, it has been argued through the concept of 'plastic sexuality' (Giddens 1992) and theorizing on 'liquid love' (Bauman 2003) that relationships in modernity are somewhat fluid, offering a fragmentary sense of sexuality and 'love'. As Giddens (1992: 2) previously noted, the concept of 'intimacy' has considerable currency, arguing that, "intimacy is a function of a 'pure relationship' whose participants are equal and engaged in interpersonal sharing." In this context, the pure relationship rests on a foundation of 'plastic sexuality', freed from the needs of reproduction offering a fragmentary sense of sexuality and 'love'. However, the applications of changing sexual scripts have not yet been examined in relation to the advertisement and consumerism of online escort services.

A social scripting perspective allowed the researcher to examine the interconnections within and across each of the distinctive escorts markets examined within this paper. The central question being whether the sexual script, advertised by escorts in the commercial sexual relationship differs significantly from that of traditional socially and culturally assigned gender roles. Social scripts have previously been understood as social agents, proposing what is considered normative within a culture, and as intrapsychic maps, providing instructions for how to feel, think and behave in particular social situations. Sexual scripts go as far as to provide guidance for the individual, consequently adding a sense of predictability as to how the individual should feel and behave. Masculine gender roles have long dictated power, general independence, assertiveness and exploration. Whereas feminine gender roles command ideals of behavioural restraint and personal control (Lippa 2001; Oliver and Hyde 1993; Wiederman 2005).

It has been well documented within the literature that online escorts who are in control of their work and working environment habitually 'act out' a sexual script to work in their favour whilst maximising financial gain and control (See Brewis and Linstead 2000; Burghart 2015; Sanders 2005). The sexual script for some sex workers has become part of a wider routine in which the sex worker and the client adopt individual roles which are played out within the commercial encounter (Sanders 2008). The manufactured identity of a sex worker is an example of creative control over the product of their labour, which in turn determines their self-image, as well as that of their customers (Marques 2006).

Emotional interactions with escorts has become a fundamental requirement of the sexual encounter for customers of escorts. Escorts services have become to generally resemble dating experiences; commonly referred to as the 'girlfriend experience' (GFE), which includes services such as a conversation, kissing and hugging (Lever and Dolnick 2010; Sharpe and Earle 2003; Weitzer 2005). Several studies go further to suggest that online escorts, in some circumstances, were expected to provide counselling and emotional support to clients, as well as providing a sexual service (Lever and Dolnick 2002). The GFE and provision of 
intimacy within the sexual encounter does not require emotional investment in the transaction, but does conflate and commodify both the psychical conduct and emotional intimacy. In this context, the provision of intimacy is presented as a valuable commodity.

This style of relationship between the sex worker and client was what Bernstein (2007: 103) referred to as 'bounded authenticity', or an "authentic emotional and physical connection" between escort and client. What is of interest to the research, is how each of the escort samples construct his or her own sexual scripts based on that individual's personal experience and social learning with their preferred clientele market.

The rise of online prostitution services is not the only reason for the expansion of sex work and market types. Social class and the socioeconomic status of sex workers, as well as their clients, are integral to understanding prostitution, especially online escorting services. According to Bernstein (2007), and Ray (2007) the social class, structure and organisation of sex workers was a key element in the construction of the online escort market, not only in the targeting of middle class clients, but in the implementation of middle class values in its self-regulatory structuring. Previous research has since supported these claims, with Ray (2007: 49) stating that "one of the most powerful changes the Internet has brought to the sex industry is that it has created a vast and visible middle class of sex workers who cater to middle-class men".

The research was concerned with the type and styles of language used within the advertisements to entice potential customers. As Bourdieu observes, one way that members of the new petite bourgeoisie have found to embrace a sense of social distinction is via the adoption of 'reconversion strategies', in which cultural capital is employed to 'professionalize' marginal spaces within the labour market and to invest them with a sense of personal meaning and ethical value (1984: 368). As Bernstein (2007: 489) noted, the previous decade had witnessed a growth in middleclass sex workers, whom she referred to as members of the 'new petite bourgeoisie' and who embraced sexual experimentation, fluidity, and independence. Such a gap in the literature reinforces the importance of my research, which examined the dominant discourses in online escort advertisements across different market types, gender, sexuality and social class. The researcher recognises that no actual distinction of the escorts social status could be fairly made, but was more concerned as to whether the escort projected a perceived social status through their advertisement.

\section{Methods}

Discourse analysis was chosen in order to tell us how male and female to male, male to male, male to female and female to female online escort markets differ in terms of online advertising and marketing patterns. Such an analysis did not argue for or against the 'truth' of specific statements in the text; rather, it focused on the existence and message of the texts, and then located them within an historical and social context (Caldas-Coulthard 1993). Discourse analysis offers the researcher the 
opportunity to apply critical thought to social situations, whilst also identifying the hidden, or not so hidden, politics entangled within socially dominant and other discourses (Caldas-Coulthard 1993).

The focus in linguistic studies has changed in recent decades from the description of formal properties of language as systems to the description of how individuals communicate with each other through the use of language (Caldas-Coulthard 1993). The discursive emphasis in this research study involved both textual and contextual aspects; focussing on the text whilst giving due consideration to its relationship to context. The examination of social structures and language, and their influence on the production and reproduction of a standardised type of service, could thereby be made visible (Lupton 1992; Stephens 2009).

The researcher was all too aware of other data collection methods being available, such as content analysis. It was felt that a content analysis approach would result in the decontextualisation of words from the discourse being examined, as Billig (1989: 206) has previously noted, in stating 'this sort of methodology can count words, but it cannot interpret them. Under some circumstances mere counting can lead to misleading conclusions'. For these reasons, the researcher felt that a discourse approach was the most suitable method for collecting detailed data when identifying the shared understanding of the escort and the client about their sexual roles, and how the language used within the advertisements sustained this type of relationship.

\section{Sampling}

The websites chosen for the research were initially identified using the search engine Google UK, due to it being ranked as the most popular search engine in online opinion polls by www.searchenginewatch.com (retrieved 23 April 2012). The scope of the study was then limited to escort services, with only four different search terms or keywords used: 'female escorts', 'gay escorts', 'straight male escorts' and 'lesbian escorts', in order to identify the relevant websites. Over $12,900,000$ results were recorded for female escorts, 10,200,000 for gay escorts, $1,490,000$ for straight male escorts, and 1,610,000 for lesbian escorts, using these search terms. In addition, two other search engines, Yahoo.com and Bing.com, were explored to certify that there was not a substantial difference in results. What is most noticeable at this point of the study are the dramatic differences in advertisements targeting male customers, rather than female customers. This initial finding alone goes so far as to suggest that despite some uptick in female sexual consumption in recent years, we are still talking about an overwhelming male customer base for escorts' services. Due to the large number of 'hits' for each of the various search terms only the first hundred displayed websites were examined. The websites chosen received the most number of hits, once online directories and agency websites were disregarded. Online directories of escort services and agency websites were disregarded, due to the directories being simply a compilation of a list of websites and therefore irrelevant to the specific search terms.

For these reasons, escorts' advertisements for this research were selected from the following four UK based websites: Punternet (www.punternet.com) for female 
escorts catering to male customers, Sleepyboy (www.sleepyboy.com) for male escorts catering for male customers, Menforhire (www.menforhire.org.uk) for male escorts catering for female customers and Firstcallescorts (www.firstcallescorts.co. uk/lesbian-escorts.php) ${ }^{1}$ for female escorts catering for female customers. Separate databases were kept for each of the four websites selected and any broken, expired, or otherwise unusable links (for example, foreign language or disguised pornographic or webcam links) were disregarded. In the first instance the advertisements were divided into different markets and analysed to determine the gender of the seller and that of their prospective customer.

For a five-week period during late 2012 ten advertisements from each of the websites were analysed - a total of forty advertisements. An attempt was made to randomise the selection of advertisements by uploading a full list of advertisements from each website every week and then randomly selecting two from each list. This selection process allowed for a more representative sample of the chosen websites within each of their monthly operations. The number of adverts posted on particular days varied greatly on the female to male and male to male advertisement websites, but was significantly less variable on the male to female and female to female escort websites. All of the examined websites organised their reviews in reverse chronological order, with the more recently posted advertisements at the top of the page. Due to the fact that the advertisements were posted daily on the different websites, the lists of reviews were constantly refreshing themselves. The effect of these listing practices thereby impeded the randomisation of the data, such that fully random sampling became impossible.

\section{Coding and Variables}

Each of the chosen escort advertisement websites was analysed separately. Then the language used in the advertisements was organised under various categories. Specific quotes within the advertisements were chosen by the researcher as it was felt that they were representative, and were selected to show range. A social scripting perspective allowed for the examination for the interconnections within and across each sexual script and market type. It also allowed for a framework in which to examine escorts and their client's sexual behaviour. In order to identify the dominant discourses used in the escort online advertisement and how they related to gender, sexuality and social class, a pilot discourse analysis led the researcher to create a thematic framework. Through recurrent appearances in the advertisements, codes were condensed into categories that were used to structure the analysis according to standard grounded theory procedures (Strauss and Corbin 1998). The decision was made to categorise the language as relating to:

1. Romance: the code 'romance' referred to language that framed the encounter or escort as romantic, intimate and sensual.

\footnotetext{
${ }^{1}$ All of the female to female escort advertisements were selected from an agency operated website and in all cases the advertisements were written in third person. This lead the researcher to assume that all of the advertisements featured were written by a third party. In addition, the researcher felt that despite the advertisements being selected from the 'Genuine Lesbian Escort Services' section of the website it was likely that the selected advertisements were also accessible to male clients.
} 
2. Safety: the 'safety' code referred to information that alluded to the escort's selfpreservation, sexual health and risk management, as well as escorts honouring their customer's safety or discretion.

3. The body: Coding around 'the body' was concerned with how the escort presented their physical appearance and also the fantasy of their body in relation to the gender and sexuality of their client.

4. Sophistication: the code 'sophistication' encompassed escorts' references to having good etiquette, being well mannered, or belonging to a particular social class.

5. Submissiveness: the code 'submissiveness' denoted descriptions of the escort's sexual role during the sexual encounter and/or the escort placing an emphasis on sexually pleasing the client.

6. One-off encounter (open invitation): the code 'one-off encounter' referred to descriptions of the escort being accessible to customers who seek their services for the purposes of sexual gratification above that of sexual intimacy.

7. Relationship (exclusive service): the code 'relationship' was concerned with examining the language that was suggestive of a relationship between the escort and client, over and above a one-off encounter.

8. Middle class cultural capital: this code was used in order to look for ways in which escort advertisements signalled the escort's own (supposed) middle class status, or in ways that escorts might try to capture and exploit their customer's interests. The study incorporated aspects of Bourdieu's (1984) model of social distinction, in order to identify escorts' displays of social and cultural capital. Bourdieu (1984) proposed that cultural products and practices allowed for classes to differentiate themselves using classifications that defined taste, and covered a variety of assorted areas, such as sports, food, art, politics and so forth.

9. Open section: this code of an open category was used for recording use of language that did not fit codes 1-8 above.

\section{Findings}

\section{Romance}

In nine out of ten cases where female to male escorts made reference to romance, reference was made to the affiliated qualities of the ideal woman in only a few words. Escorts typically presented themselves using the words 'sensual', 'romantic' or 'flirtatious'. As Lakoff (2004: 42) has commented, in order to appeal to and attract the attention of men, a 'woman's language' might need to sound 'frilly' and 'feminine', to align with masculine notions of the idea of femininity. References to 'romantic' discourses were often far more apparent and elaborate in the male to female escort advertisements. The proposing of a romantic experience was typically displayed in a chivalrous heteronormative fashion. As one male to female advertisement promised the female client, 'Confident young man with a romantic 
and passionate side' with a 'something very special quality'. In other adverts, escorts were flirtatious in their language, for example: 'The words can flow on that page but will be just words, is [sic] better to describe myself whispering into your ear'. In stark contrast, none of the male to male advertisements made reference to romance. Regardless of the limited lists of attributes, distinctions can be drawn to suggest romantic and more intimate services, with several gay escorts claiming to offer the 'Boyfriend Experience' (BFE). Escorts stating that they would be willing to provide the client with a 'BFE', or 'GFE' in the case of the female escorts, were commonly referring to their willingness to provide their customers with services such as kissing, hugging, caressing and mutual oral sex acts, as required (Holt and Blevins 2007; Sanders 2004). Again, although not using a romantic discourse, the advert gave a clear sense that the client could expect a greater depth to the sexual encounter, beyond the act of mechanical sex. Similar to their female to male counterparts, most of the female to female escort advertisements featured in the discourse analysis made reference to the offering of romance. One female to female escort advertisement stated; '...Perfect company for a romantic evening or a luxury weekend away...' and '...very open minded, romantic and charming, making her the perfect GFE companion...' In all cases, emphasis was placed on the escort's role of providing the client with a sexual romantic experience.

The findings relating to the code romance highlight the extent to which romance is sold far more commonly and overtly to female customers of escorts, rather than male ones. What is also interesting to note is that this applies regardless of whether the male or female customer is buying from a male or female escort. Whereas, those escorts advertising towards male clients barely made reference to romantic discourse, but did however in most cases offer emotional services by advertising their willingness to provide ' $G F E$ ' or ' $B F E$ '.

\section{Safety}

Concerns over safety, in the form of risk management strategies, began, for a handful of escorts, in the wording of their online escort advertisement. Concerns in relation to safety within the female to male advertisement sample involved the escort's self-preservation through the limiting of the body parts and services offered. Despite none of the escorts explicitly stating that they would not engage in a particular sexual act, it was more than likely that they would not directly advertise the lack of a sexual act, but would instead use a disclaimer of some sort. For example, one of the escort's advertisements stated, 'Do not miss out. Most services offered'. Other concerns around safety related to the escort requiring the client to reveal some sort of identity, be it through email, thus traceable through their computer's IP address, or a telephone number, for example: 'Sorry no appointments will be accepted by text message or withheld number'.

Male to female escorts tended to place a far greater emphasis on looking like a genuine male companion, and offered assurances that they would uphold the contract: 'I can fit into [sic] environment \& situation with extreme ease so be rest assured, your secret is safe'. Other references to safety involved offering assurance that the client would have a 'comfortable, safe, exciting and enjoyable time no 
matter the occasion'. In most cases, it is virtually always the female party's safety that is at issue. Limited references to safety were also noted within the male to male advertisements, with those that did reference it focusing on safe sex: 'I only ever play safe, no exceptions to the rules' and '...Safe only please. I don't do barebacksafe sex only'. These statements alone appear to tap into the discourse surrounding gay sex and HIV status, and were suggestive of deterring potential customers from requesting bareback sex, whilst reinforcing a professional code of conduct.

References to safety with the exception of male to male escorts' advertisements, reveal how it is virtually always the female party in the encounter (in an encounter with a man) that is at issue; reflecting a wider dimension that within the sex industry women are perceived to be most at risk in prostitution encounters, whether they are the sellers or buyers. Personal safety concerns also appear to be less of a priority for female to female escorts, with only a handful of the advertisements analysed making any reference to safety, and where mentioned it was in the form of a legal disclaimer. Again, perhaps the most obvious explanation is that these advertisements are for encounters in which no man will be involved. Placing the escort at significantly less risk.

\section{The Body}

All of the female to male escort advertisements placed an emphasis on selling the body' through language and photographic images. The body was mostly described in the form of 'stats', and in a handful of cases in a more descriptive manner. Regardless of the style of writing, all of the advertisements placed an emphasis on parts of the body that were culturally-constructed as sexually attractive in women in western societies, (Hakim 2010; Wiggins 1968), such as legs, breasts or bottom, for example; 'Attractive blond in my mid 40s, leggy 5'8 ft tall, toned and tanned size 10/12 body with $36 D$ breasts'.

Female to male escorts were also the only escort sample to identify the characteristics of their services by offering up a variety of embodied performance, such as 'See me in many of my different outfits, rubber, PVC, naughty nurse, or sexy secretary or just my sex underwear'. Many of the female to male escorts also offered their customers a role playing service, from 'School girl-NurseSecretary-slave girl-Prisoner-Head Girl to Naughty Niece and much more'. The fact that it was only female escorts selling to male customers being called upon to roleplay in these ways adds a further power dynamic to the sexual encounter. Not only are female escorts' services purchased with the emphasis on the attractiveness of specific body parts, but also on their ability and willingness to provide the customer with multiple sexual characters dependent on his sexual desire.

Nudity, and in some cases pornographic images, were also a common occurrence. In most advertisements, female to male escorts displayed either their breasts, vagina or bottom, and within those cases, two of the advertisements displayed pornographic images, with one example being two women engaging in oral sex.

For male to female escorts the body was represented in terms of a style, and not as a collection of body parts. Descriptions of the body were all given in a more vivid manner, and not in the form of 'stats'. Instead male to female escorts commonly 
referred to their presentation, height, build, or personal fitness: 'I really enjoy sport and keeping fit which means gym training, cycling, kickboxing and gymnastics'. Most of the escorts clearly indicated that they had 'impeccable presentation' [sic], with some even boasting 'a variety of outfits to suit all occasions whether indoors or outdoors'. Emphasis on the male escort's height was also a central feature in all of the advertisements (e.g. 'Ex Army Gentleman, height: 6:2'), perhaps reflecting a wish to play into the stereotype of the tall, dark, handsome stranger. More often than not, male to female escorts used sexual innuendos within the advertisements instead of specifically referring to their sexual body parts. For example: 'I am a hot, ripped athletic, masculine and horny with a lot of stamina'. What is also interesting to note, is that none of the male to female escorts displayed any images of male genitalia, although in most of the advertisements they did display their torso and a headshot. This may be because male escorts believed that potential female customers preferred escorts to present themselves as linguistically competent gentlemen, preferring to include a full descriptive account of their character and the potential dating experience within their advertisements, rather than in the context of a collection of body parts.

Similarly, all of the male to male escorts provided details of their height, build, and weight, but also included the size of their penis. Typically, most of the male to male escorts described their physique in the form of 'stats', but some chose to give more elaborate descriptions in addition. For example: '...FIT SEXY BRITISH LAD, BROWN HAIR \& BLUE EYES WITH A BIG COCK...' Male to male escorts emphasised, within their advertisements, the most detail by far with regard to their sexual organs. This can only suggest, that gay escorts feel that the size and length of their penis is fundamental when it comes to attracting male clients. In all cases the male to male escort showed pornographic images of an erect penis, as well as other male body parts.

Female to female escorts also commonly described the body in the form of 'stats' or in a more descriptive sexual manner. For example, in the form of 'stats': Age 20, Height 5.5, Stats: 34B, Dress 8, Hair Brunette, Eye colour Brown' or in a more descriptive fashion, '... She has a real zest for life; keeping fit, ensuring her sexy body is always in shape'. Most, like their male to female counterparts, included descriptions and photographs of the body, which were often more sophisticated, and only one of the advertisements displayed a semi-nude photograph. As with their male to female counterparts, this may have been because female escorts wished to present themselves as linguistically competent companions rather than sexual commodities.

Discourse identified relating to the code 'the body' within the advertisements has highlighted stark differences between those escorts selling advertising towards male clients, and to those advertising towards female customers. It is clear that male customers put a much higher emphasis on escorts presenting themselves as an explicit collection of body parts, whereas those escorts selling to female customers were more likely to present the body as a descriptive subject. What was also seemingly obvious was that male customers of escorts demanded far higher levels of nudity on the behalf of the escorts; in several cases the advertisements had a pornographic content. 


\section{Submissiveness}

In nine of the advertisements, female to male escorts used language to imply that they were willing to adopt a sexually submissive role within the encounter through statements such as 'I want nothing more than to give you pleasure'. All references to 'submissiveness' were suggestive of the escort's willingness to please the customer. This reinforced the fulfilment of the male client's fantasy and the perception of the ideal relationship with a woman. In contrast, only two of the male to female escort advertisements were noted as referring to the male escort's submissive role in the encounter, although in both cases these references were subtle. For example: '... I love women that make me laugh, or can teach me something' to 'I'm happy to let you take control'. In these particular examples, the escort was informing the potential client that he was willing to be less dominant in the encounter. In other advertisements, male to female escorts were far more open about the dominant sexual role they will take in the encounter. For example: 'masculine and horny with a lot of stamina and fun. I am gentle but can be rough when the occasion requires it'. Despite the style and type of language used to refer to the male to female escort's role within the client-encounter, the language within the advertisements was still suggestive that the female customer would adopt a submissive sexual role within the encounter.

As a result of the standardised template used for the advertisements, male to male escorts who used the advertisement host website, were asked to define their sexual role in the encounter. Seven of the escorts stated they would be willing to give and receive penetrative sex under the heading 'role', therefore appealing to a wider category of clientele. In these cases the code 'submissiveness' held a narrow meaning. Surprisingly, none of the female to female advertisements analysed made reference to the escort's submissiveness or submissive role within the encounter. Again this may be suggestive of the power and gender equality between two females in a sexual encounter.

Distinct differences were highlighted in regard to the submissive role the escort or the customer plays in each of the escort markets sampled. What is clear is that female to male advertisements suggested submissiveness on the part of the escort, whilst male to female escorts were suggestive of dominance on the part of the escort. In both cases, what is being clearly advertised here is male dominance and female submission structured around the standard patriarchal heteronormative sexual script.

\section{'One-Off Encounter'}

Interestingly, references to the offering of a 'one-off encounter' were only noted in the female to male and male to male escort advertisements. Half of the female to male escorts made reference to the provision of a 'one-off encounter'. Some did so indirectly and implied their sexual repertoire, as in 'Cum as many times as you like, within your booking time or '30 min sessions available'. Other advertisements within the female to male escort sample also clearly set time limits of availability for their services. For example; 'I am available Monday to Friday 11am-6pm for 
discreet in call services'. Time constraints, as stated above and within some of the female to male advertisements, stand in stark contrast to the suggestion in other advertisements that the client could buy a relationship that would continue to exist beyond the specific encounter. The language used in some of the escort advertisements, which was short and to the point, implied an impersonal approach, which related specifically to the requirements of providing their customers with sexual gratification.

Male to male escorts were far more likely than any of the other online escort sample groups, to solely refer to the encounter, and offer nothing beyond it in terms of a relationship. This was evident in the language used by male to male escorts, such as '...A GENUINE BIG AND THICK COCK FOR YOUR PLEASURE' to 'Cum and unload'. Like most of their female to male counterparts, male to male escorts, in most cases, explicitly stated that they were willing to engage short sexual services with any potential male client.

Strikingly references to the offering of a 'one off encounter' were only in the advertisements targeted towards male customers. This is suggestive that male customers are more likely to seek the services of escorts for instantaneous sexual gratification, rather that sexual intimacy and companionship. Escorts advertising to male customers were also far more likely to advertise that they were available for short sexual encounters, and more likely to advertise their willingness to provide specific sexual acts, such as oral sex, alone. Whilst on the opposite end of the spectrum escorts advertising to female clients make the assumption, through their advertisements, that their customers are seeking a combination of sexual companionship, intimacy and leisure.

\section{Relationship (Exclusive Service)}

References to the provision of a 'relationship' in female to male advertisements often related to language in the context of the escort's presumed role in fulfilling male fantasy or to the escort offering the client unlimited access. For example: '... I would be happy to arrange an evening tailored especially to your taste' or '...available for overnights or long weekends away...'. The use of language often demonstrated how the female to male escort indirectly allowed the client to uphold a degree of ownership over her during the encounter, 'I will be your someone who will ensure a pleasurable and relaxing time together'. In addition, eight of the female to male advertisements claimed to offer the 'girlfriend experience'. For example; 'If you are looking for a Real Girlfriend Experience and a lot more' or 'GFE available'. Another noted discourse concerned the escort offering assurance to their customers that they would deliver a high standard of personalised service, which they suggested would leave the client wanting more.

Similarly, most male to female escort advertisements placed an importance on ensuring the female client has a 'safe, relaxing and enjoyable time'. For example, 'I love to make a fuss of those I am with and make sure they are enjoying themselves', demonstrating to the client that the male escort was willing to provide a relationship based on romance above that of sex. Like their male to female counterparts, all of the female to female advertisements included the offer of a relationship, varying 
from the offering of an intimate relationship to companionship. One escort, for example, was described thus: '...Her clientele are all in love with her...'. Others were described as good companions: '...Perfect company for a romantic evening or a luxury weekend away...'. These findings suggest that escorts who advertised for female customers believed that they valued romantic companionship in some form far more than male customers did.

Once again the findings for the code 'relationship' has highlighted the extent to which male customers' of sex workers place more of a demand on sexual activity, rather than sexual intimacy. What was again also noticeable was that escorts selling sexual services to female customers, marketed in such a way to assume that their customers sought sexual intimacy and companionship, above that of mechanical sex set in a short time frame.

\section{Sophistication}

References to sophistication were made in half of the female to male advertisements sampled, where, in all cases, escorts described themselves as 'elegant' or a 'lady'. West and Zimmerman have suggested that being 'ladylike' meant that a woman was 'subject to assessment, in terms of normative conceptions of appropriate attitudes and activities for her sex, she was therefore essentially feminine' (1987: 139-140). By the escort suggesting that she behaved in a certain manner and upheld a degree of social etiquette, she was indirectly implying that any potential customer should treat her in a respectful way, and as a result this appealed directly to a specific type of clientele, presumably one that would keep her safe.

Similar to their female counterparts, references to sophistication in the male to female sample were, at times, presented in the form of Victorian quasirespectability. Many of the advertisements made reference to the escort being a 'gentleman' or their role as a gentleman in the encounter. For example, 'I am a down to earth English gentleman' to 'and by the way I was brought up to be the perfect gentleman (and I guess it's perhaps a sad sign of the times that some people don't appreciate that quality in a guy!)'. Such a comment arguably plays into nationalism and stereotypical imagery. In this respect, the escort was selling himself as an 'old romantic' whose services abided by chivalrous codes of conduct. In this context, the escort put forward the offer of companionship before any sexual activity, which perhaps could have put some female customers at ease, if they were seeking companionship rather than sex.

Discourses relating to 'sophistication' were undetectable in both the male to male and female to female escort sample. Instead the central theme of the male to male advertisements would appear to be the selling of the self and the body. It is indeed striking to note that it was only the same sex advertisements that lacked any references to sophistication. This highlights the extent to which displays of sophistication, where the demand for sexual services is concerned, is connected to differing heteronormative codes of gender and sexual scripts. 


\section{Traditional Ideas About Middle Classes}

Language relating to the escort's education, or level of education, was only noted in three of the female to male escort advertisements, delivered in the form of a brief disclosure. For example, 'open and educated mind in and out of the bedroom', or, as in this reference to the escort's type of charisma, 'Elegant and educated yet down to earth lady who loves to please a gentleman'. References to female escorts 'education' across both markets were brief and made in passing reference. Perhaps suggestive that female escorts did not wish to been seen to challenge the status quo of the encounter. Male to female escorts also made reference to their education in only a handful of cases. However, in all the cases where education was mentioned, male escorts were far more descriptive in the language they used to describe the type and level of education received. For example: 'My name is Matthew, a 34 year old public school boy and a degree educated guy who works in the media'. Despite the lack of references to the escort being 'educated' in most of the male to female advertisements, other terms were used by these escorts to emphasise that their character was that of the 'gentleman'.

Education was only mentioned within two of the male to male advertisements, and in both cases with fleeting reference: 'Intelligent, well-educated, energetic and outgoing' and 'Well travelled, articulate, educated and always discreet'. Both references were put forward in the context of providing a rounded view of the escort's character, and did not specifically provide any details as to the escort's level of education. Similarly, two references were noted within the female to female advertisements to the escort herself being educated, or having received an education. These were set within a brief context and in both cases were part of a sexual innuendo: 'University educated and highly cultured making for fascinating and delightful company both in and out of the boudoir'. Here again the escort's education was discussed in a brief passing reference.

In the female to male escort sample, unlike the other online escort advertisement samples, none of the escorts gave any specific mention to being well travelled or having a desire to travel. Only one of the female to female escort's advertisements made reference to travel, albeit fleetingly. Unlike their female counterparts, the majority of male to female escort advertisements made reference to their travel experience or passion for travel. Similar to the data collected under the code 'educated', references to travel were made in relation to the escort being of a particular character. For example: 'Well travelled \& very knowledgeable on most subjects ...'. At times the male to female escorts brought together their experience of travel and education to boast that they spoke a variety of languages: 'Speaking four languages and with a vast abroad experience I'm sure you will like me'.

Due to the pro forma template within all of the male to male escort advertisements, all male to male escorts were asked, under a subheading, to identify their 'dream holiday'. Answers given tended to fall into these two categories: 'The company is more important than the location' to 'Anywhere hot with a beach very close'. However, it was not felt by the researcher that this alone expressed that the escort was well travelled, or even had a desire to travel, as they were obliged to list something under the set pro-forma heading. 
Again, it was the male to female escorts who made the most references to 'food and drink', and this was done in a variety of ways, from expressing their 'love of fine dining and red wine' to dining out being one of their favourite hobbies: 'At risk of sounding clichéd, my hobbies and interests include travel and adventure, going to the theatre and cinema, wining and dining...'. The fact that most of the male to female escorts expressed a liking for 'dining out' suggested that this was an activity they believed their customers expected of them. Only one reference was made to enjoyment or preference for 'food and drink' in each of the other advertisement samples. The lack of reference within the advertisements to the code 'food and drink', with the exception of male to female escorts, suggests that escorts believed that their customers placed little value on themselves as non-sexual companions. Additionally, male to female escorts were the only group to use any language that related to the code 'culture', including the escort saying he was cultured-'I am a down to earth English gentleman who believes in old-fashioned-values'; enjoyed culture-'I like to live a healthy lifestyle, enjoys the arts \& theatre, fine wines \& the -outdoors'; or had a desire for or enjoyed attending cultural events: 'I enjoy cultural events'.

None of the female to male escorts' advertisements sampled made any reference to the code 'hobbies and leisure pursuits', and only one reference to hobbies was made within the male to male and female to female advertisements. There were assorted references in the male to female advertisements to a range of leisure pursuits, such as 'Adventurous person likes good life' and 'I enjoy keeping fit and healthy eating'. The language used once again reinforces the perception of the escort having a fit physique and being traditionally masculine.

\section{Discussion}

Whereas gendered codes adopted within the advertisements have allowed us for a deeper understanding as to what the customers of escorts want and expect from the encounter, in turn the findings provide us with very little evidence to support the notion that escorts would be able to create and utilise a market place where they are free to play with gender and sexuality, as set out in the arguments by Bernstein (2007) and others earlier in the literature. Nor have the online advertisements been able to tell us anything in regard to what the actual seller endorses and believes. Instead what we witnessed is an online marketplace still very much constructed around heteronormative sexual scripts in relation to dominance and power.

The findings have largely highlighted the extent to which online escorts' services are very much bounded by the traditional socially and culturally constructed perceptions, that men want sex and women want romance, a cliché seen in much of wider society. As Oritiz-Torres et al. (2003) have noted, men are socially and culturally conditioned within western cultures to desire sexual intimacy earlier in courtship than women, while for women sexual intimacy tends to be embedded in the context of love and romance. The findings of the research have identified that despite sex workers being able to utilise a virtual space, whereby they can challenge sexual representation and self-presentation, escorts appeared to adopt cultural 
prescriptions of gendered sexual roles of dominance and sexual objectification through the use of sexual scripts. It was clear from the advertisements in relation to gender that the masculine role dictated general independence, assertiveness and exploration. However, feminine gender roles are based on ideals of behavioural restraint and personal control. In turn, lending a sense of predictability as to how the client should feel and behave, as well as what the client might expect from the encounter. Furthermore, Hynie et al. (1998) noted in their study that men felt a desire for fun and physical desirability as motives for sex, while female participants were far more likely to express that love, commitment and emotional intimacy were the main motivators for having sexual intercourse. This would appear to signify why the male to male, and in some cases female to male, escorts felt that when advertising to male customers they needed to be, or felt like they should be, more explicit.

At the opposite end of the spectrum both male and female escorts advertising to female customers commonly presented the body as a subject and did not directly express their sexual role or preference; instead using sexual innuendo within their adverts. Escorts not revealing their preferred sexual role within their advertisements may indicate a wish to display a message of gender neutrality, in the sense of allowing their female client to lead in relation to sexual roles. However, the findings also revealed that when advertising their services to female customers, male to female escorts, and to a lesser extent the female to female market, were far more forward in advertising a romantic dating experience. This arguably lends support to traditional heteronormative theories, which have portrayed men as the initiators of sexual activity and women as more interested in courtship (Byerts 1996).

The roles assigned to male and female escorts and to their male customers, through the implicit messages embedded in the escort advertisements, conform to the argument set out by Lakoff (2004), that women are socialised into using a particular style of language through which their inferior position is reinforced. The findings of this study lead me to argue that instead of escorts having been conditioned into using a certain type of language, in order to sound appealing to the opposite sex, as argued previously by Lakoff 2004); instead escorts exploit, capitalise on and manipulate their use of language to deliberately play into the stereotypical sexual desires of their desired customer. What the escort was offering was a realisation of their fantasy, with respect to behaviour and beauty, of the ideal man or woman. In this context what the escort sells are those body parts which they calculatingly choose to objectify, as a result capitalising on their 'erotic capital' (Hakim 2010). Although, whether such represented fantasies within the use of their advertisements are a reflection of their potential customers' desires or a true representation of the type of service that their customers can expect remains to be considered in future research.

The findings of this study have also revealed that discourses relating to social class were not an essential theme within the advertisements, but that they provided an important backdrop. Dominant discourses relating to education, travel, food and drink, and preferred leisure pursuits and hobbies were only mentioned in a handful of female to male, male to male and female to female escort advertisements. These findings very much suggest that escorts who advertise their sexual services to male 
customers feel it is irrelevant to include personal information, to the point that their male customers would find this information intimidating and not relevant to their sexual fantasies. It would also appear that female to male escorts were far more likely to present themselves as a 'blank canvas' for their client's fantasy to be played out on. It may not be surprising to learn that male to female escorts were far more likely to demonstrate their economic and cultural capital within their advertisements, specifically in the areas of education, travel, food and drink, and culture.

\section{Conclusion}

The findings of this research contribute to the body of literature on technology and sex work, which is growing, although gradually, through investigating how escorts advertise their sexual services to customers via the Internet. Through this research we now have a gendered overview of the ways in which male and female escorts advertise according to the sexual desires of their customers, further contributing to debates around sex work and sexual behaviour. This research has also identified how language was used by each of the genders; with the language and photographs being used reinforcing the dynamics of male and female power and relationships. The findings have highlighted that escorts uphold the socially constructed view that the language used should conform to traditionally assigned roles. What was striking was that there was no evidence to suggest otherwise, and that male and female escorts were not attempting to challenge cultural prescriptions of gendered sexual roles of dominance and sexual objectification. The traditional sexual division of labour was ever more emphasised by the language used by escorts in order to present the 'ideal woman' or 'ideal man' image. In fact, arguably, the fantasies being catered to are those of the buyers, not the sellers.

As discussed within the earlier literature, a growing body of academics argue that Internet technologies and communications have created a space where the online escorts are 'free to play' with gender and sexuality, whereby gender norms and sexual stereotypes can be explored and challenged. In fact, what this study has revealed and previous academics have failed to consider, is that it is the customers' demands that have come to shape the very nature of the online escorts market. Furthermore, it appears that escorts have chosen to exploit, capitalise on and manipulate this demand through their use of language. As we witness in any given market it is the customer that shapes the demand and it is the sellers' role to meet those demands and this is exponentially truer when it comes to the selling of online sexual services.

\section{Compliance with Ethical Standards}

Conflict of interest No conflict of interest.

Human and Animal Rights All procedures performed in studies involving human participants were in accordance with the ethical standards of the institutional and/or national research committee and with the 1964 Helsinki declaration and its later amendments or comparable ethical standards. 
Informed Consent Informed consent was obtained from all individual participants included in the study.

Open Access This article is distributed under the terms of the Creative Commons Attribution 4.0 International License (http://creativecommons.org/licenses/by/4.0/), which permits unrestricted use, distribution, and reproduction in any medium, provided you give appropriate credit to the original author(s) and the source, provide a link to the Creative Commons license, and indicate if changes were made.

\section{References}

Agresti, B. T. (2009). E-Prostitution: A content analysis of Internet escort websites. Unpublished thesis, The George Washington University: Washington.

Ashford, C. (2009). Male sex work and the Internet effect: Time to re-evaluate the criminal law? Journal of Criminal Law, 73, 258-280.

Bauman, Z. (2003). Intimations of postmodernity. London, New York: Routledge.

Bernstein, E. (2007). Temporarily yours: Intimacy, authenticity, and the commerce of sex. Chicago: The University of Chicago Press.

Billig, M. (1989). The argumentative nature of holding strong views: A case study. European Journal of Social Psychology, 19(3), 203-223.

Bourdieu, P. (1984). Distinction: A Social Critique of the Judgement of Taste. Cambridge, Mass.: Harvard University Press.

Brents, B., \& Hausbeck, K. (2007). Violence and legalised brothel prostitution in Nevada: Examining safety, risk and prostitution policy. Journal of Interpersonal Violence, 20(3), 270-295.

Brewis, J., \& Linstead, S. (2000). Sex, Work and Sex Work: Eroticizing Organization. New York: Routledge.

Burghart, K. (2015). Escorts.co.uk: An examination of four distinctive online escort markets $\mathrm{Ph} . \mathrm{D}$. Thesis, Royal Holloway University of London. Unpublished.

Byers, E. S. (1996). How well does the traditional sexual script explain sexual coercion? Review of a program of research. Journal of Psychology \& Human Sexuality, 8(1-2), 7-25.

Caldas-Coulthard, C. R. (1993). From discourse analysis to critical discourse analysis: The differential representation of women and men speaking in written news. Techniques of Description: Spoken and Written Discourse, 196-208.

Capiola, A., Griffith, J. D., Balotti, B., Turner, R., \& Sharrah, M. (2014). Online escorts: The influence of advertised sexual orientation. Journal of Bisexuality, 14(2), 222-235.

Castle, T., \& Lee, J. (2008). Ordering sex in cyberspace: A content analysis of escort websites. International Journal of Cultural Studies, 11(1), 107-121.

Cunningham, S., \& Kendall, T. (2009). Prostitution 2.0: The changing face of sex work. Journal of Urban Economics, 69(3), 273-287.

Giddens, A. (1992). The Transformation of Intimacy: Sexuality, Love and Eroticism in Modern Societies. California: Stanford University Press.

Hakim, C. (2010). Erotic capital. European Sociological Review, 26(5), 499-518.

Holt, T. J., \& Blevins, K. R. (2007). Examining sex work from the client's perspective: Assessing johns using on-line data. Deviant Behavior, 28(4), 333-354.

Hynie, M., Lydon, J. E., Cote, S., \& Wiener, S. (1998). Relational sexual scripts and women's condom use: The importance of internalized norms. Journal of Sex Research, 35(4), 370-380.

Illouz, E. (1997). Consuming the romantic utopia. Berkeley: University of California Press.

Lakoff, R. T. (2004). Language and woman's place: Text and commentaries. New York: Oxford University Press.

Lever, J., \& Dolnick, D. (2002). Customersand call girls: Seeking sex and intimacy. In R. Weitzer (Ed.), Sex for sale: Prostitution and the sex industry. New York: Routledge.

Lever, J., \& Dolnick, D. (2010). Call girls and street prostitutes: Selling sex and intimacy. In Sex for sale: Prostitution, pornography, and the sex industry (pp. 187-203).

Levitt, S., \& Venkatesh, S. A. (2007). An empirical analysis of street-level prostitution. University of Chicago and Columbia University. Unpublished.

Lippa, R. A. (2001). On deconstructing and reconstructing masculinity-femininity. Journal of Research in Personality, 35, 168-207. 
Lupton, D. (1992). Discourse analysis: A new methodology for understanding the ideologies of health and illness. Australian Journal of Public Health, 16(2), 145-150.

Marques, O. (2006). Discourses of inequality: Current solicitation laws and their effects on sex workers. Canadian Sociology and Anthropology Association 2006 Annual Meeting York University, Toronto, $\mathrm{ON}$.

Milrod, C., \& Martin, M. (2012). The hobbyist and the girlfriend experience: Behaviours and preferences of male customers of internet sexual service providers. Deviant Behaviours, 33(10), 792-810.

Oliver, M., \& Hyde, J. (1993). Gender differences in sexuality: A meta-analysis. Psychological Bulletin, 114, 2951.

Ortiz-Torres, B., Williams, S. P., \& Ehrhardt, A. A. (2003). Urban women's gender scripts: Implications for HIV prevention. Culture, Health \& Sexuality, 5(1), 1-17.

Parsons, J. T., Koken, J. A., \& Bimbi, D. S. (2004). The use of the Internet by gay and bisexual male escorts: Sex workers as sex educators. AIDS Care, 8, 1021-1035.

Pruitt, Matthew V., \& Krull, Amy C. (2010). Escort advertisements and male patronage of prostitutes. Deviant Behavior, 32(1), 38-63.

Ray, A. (2007). Sex on the open market: Sex workers harness the power of the Internet. In K. Jacobs, M. Janssen, \& M. Pasquinelli (Eds.), C'lick Me: A Netporn Studies Reader (pp. 45-68). Amsterdam: Institute of Network Culture.

Sanders, T. (2004). Controllable laughter: Managing sex work through humour. Sociology, 38(2), 273-291.

Sanders, T. (2005). It's just acting: Sex workers' strategies for capitalizing on sexuality. Gender, Work and Organization, 12(4), 319-342.

Sanders, T. (2008). Male sexual scripts: Intimacy, sexuality and pleasure in the purchase of commercial sex. Sociology, 42(3), 400-417.

Scott, J. (1998). Changing attitudes to sexual morality: AM cross-national comparison. Sociology, 32(4), $815-845$.

Sharpe, K., \& Earle, S. (2003). Cyberpunters and cyberwhores: Prostitution on the Internet. In Jewkes, Y. (Ed.) Dot. cons: Crime, deviance, and identity on the internet. Cullompton: Willan.

Stephens, H. (2009). The "Pretty Woman" fairytale and other fantasies: An analysis of the language of Yellow Pages escort services advertisements. Australia: Griffith University. Unpublished.

Strauss, A., \& Corbin, J. (1998). Basics of qualitative research techniques. Sage publications.

Van Zoonen, L. (2002). Gendering the Internet: Claims, controversies and cultures. European Journal of Communication, 17(1), 5-23.

Walby, K. (2012). Touching encounters: Sex, work, and male-for-male internet escorting. Chicago: University of Chicago Press.

Walther, J. B. (1994). Interpersonal effects in computer-mediated interaction: A meta-analysis of social and antisocial communication. Communication Research, 21, 460-487.

Weitzer, R. (2005). New directions in research on prostitution. Crime, Law, and Social Change, 4-5, 211-235.

Weitzer, R. (2007). The social construction of sex trafficking: Ideology and institutionalization of a moral crusade. Politics \& Society, 35(3), 447-475.

Weitzer, R. (2010). The mythology of prostitution: Advocacy research and public policy. Sexuality Research and Social Policy, 7, 15-29.

Wellings, K., Collumbien, M., Slaymaker, E., Singh, S., Hodges, Z., Patel, D., et al. (2006). sexual behaviour in context: A global perspective. The Lancet, 368(9548), 1706-1728.

West, C., \& Zimmerman, D. (1987). Doing gender. Gender \& Society., 1, 125-151.

Wiederman, M. W. (2005). The gendered nature of sexual scripts. Family Journal, 13, 496-502.

Wiggins, J. S. (1968). Personality structure. Annual Review of Psychology, 19(1), 293-350.

Young, K. (2008). Internet sex addiction. Risk factors, stages of development, and treatment. American Behavioral Scientist, 52(1), 21-37. 